\title{
Cross-Sectional Imaging of Third Molar-Related Abnormalities
}

\author{
(D) R.M. Loureiro, (DD.V. Sumi, (D) H.L.V.C. Tames, (1) S.P.P. Ribeiro, (D) C.R. Soares, (D) R.L.E. Gomes, and (D) M.M. Daniel
}

\section{ABSTRACT}

SUMMARY: Third molars may be associated with a wide range of pathologic conditions, including mechanical, inflammatory, infectious, cystic, neoplastic, and iatrogenic. Diagnosis of third molar-related conditions can be challenging for radiologists who lack experience in dental imaging. Appropriate imaging evaluation can help practicing radiologists arrive at correct diagnoses, thus improving patient care. This review discusses the imaging findings of various conditions related to third molars, highlighting relevant anatomy and cross-sectional imaging techniques. In addition, key imaging findings of complications of third molar extraction are presented.

ABBREVIATIONS: $\mathrm{CBCT}=$ cone-beam $\mathrm{CT} ; \mathrm{MDCT}=$ multidetector-row $\mathrm{CT}$

T

hird molars, or wisdom teeth, are a more common source of pathologic conditions than other teeth. They are the last teeth to develop and usually fail to erupt correctly. Impacted third molars have been associated with inflammatory and infectious conditions as well as development of cysts and tumors. ${ }^{1}$ Furthermore, third molar extraction is a widespread procedure in clinical practice with the potential for multiple complications. ${ }^{2}$

Although dedicated dental images are not performed in some radiology services, the teeth are often included in examinations of the head and neck. Third molar-related abnormalities can be incidental findings or the cause of a patient's symptoms. This review discusses the imaging findings of various pathologies related to third molars, highlighting the relevant anatomy and describing cross-sectional imaging techniques. Finally, key imaging findings of complications of third molar extraction are presented.

\section{ANATOMY}

The third molar is the most distal tooth located in each quadrant of the permanent dentition and is absent in the primary dentition (the deciduous dentition or temporary "baby teeth"). ${ }^{3}$ Third

Received April 7, 2020; accepted after revision June 19

From the Department of Radiology, Hospital Israelita Albert Einstein, São Paulo, SP, Brazil.

Previously presented in part at: Jornada Paulista de Radiologia, May 2-5, 2019; São Paulo, Brazil.

Please address correspondence to Rafael Maffei Loureiro, MD, Hospital Israelita Albert Einstein, Department of Radiology, Av. Albert Einstein, 627/701, 05652-900 São Paulo, SP, Brazil, e-mail: rafael.loureiro@einstein.br; @RMaffeiLoureiro

- Indicates open access to non-subscribers at www.ajnr.org

Indicates article with supplemental on-line photos.

http://dx.doi.org/10.3174/ajnr.A6747 molars usually erupt between 18 and 25 years of age. ${ }^{4}$ Every tooth is anatomically divided into a crown and a root by the cementoenamel junction. The crown is the outer portion exposed in the oral cavity, and the root is the portion covered by the alveolar ridge (Fig 1). ${ }^{3}$ Each crown has 5 free surfaces. In the case of the molars, the surfaces are named as follows: mesial, distal, buccal, lingual, and occlusal, referring to the anterior, posterior, lateral, medial, and biting surfaces, respectively. ${ }^{4}$ Third molars have a square-shaped crown with a large and irregular occlusal surface suitable for shearing and grinding food and usually have 3 roots, though the number is variable. ${ }^{5}$

The maxillary third molars can have a close anatomic relationship with the maxillary sinus floor, depending on the length and divergence of their roots and the degree of pneumatization of the maxillary sinus. This close relationship increases the risk of developing odontogenic sinusitis as well as an oroantral fistula after dental extraction. ${ }^{6}$

The mandibular third molars are the teeth closest to the mandibular canal, which contains the inferior alveolar neurovascular bundle. This close relationship poses a risk of injury to the inferior alveolar nerve during dental procedures, particularly mandibular third molar extraction. ${ }^{7}$

\section{CROSS-SECTIONAL IMAGING METHODS}

Cone-beam CT (CBCT) and multidetector-row CT (MDCT) are able to evaluate the teeth and adjacent bone with submillimeter spatial resolution, allowing for multiplanar reformatting and $3 \mathrm{D}$ reconstruction. ${ }^{8,9}$

CBCT uses a pulsed conic or pyramidal x-ray beam and a flat panel detector and performs a single rotation in a circular path around an isocenter to obtain images. ${ }^{8} \mathrm{CBCT}$ involves less radiation 


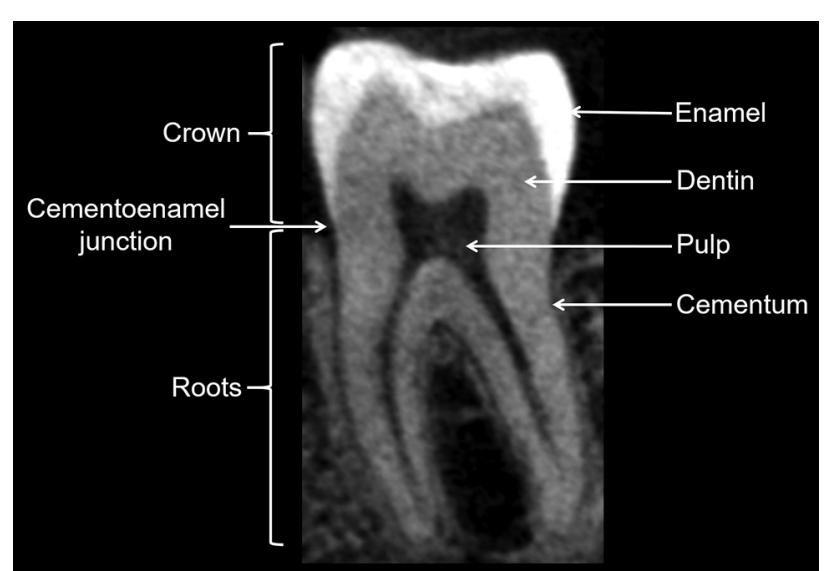

FIG 1. Anatomy of a normal molar tooth. Sagittal CBCT image shows the 3 mineralized hard tissues (enamel, dentin, cementum) and the pulp. The enamel is the outermost layer of the crown, and the root is enveloped by a thin layer of cementum. The dentin is isoattenuating to the cementum and hypoattenuating to the enamel. The pulp contains the neurovascular elements.

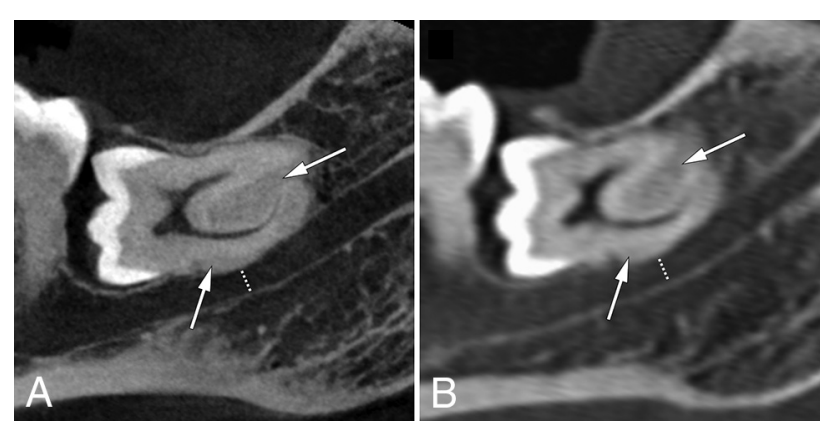

FIG 2. Horizontal unerupted impacted third molar. Sagittal CBCT $(A)$ and MDCT $(B)$ images show an unerupted third molar impacted in the second molar. A close relationship between the third molar and the roof of the mandibular canal, hypercementosis around the roots (arrows), and mild reduction of the caliber of this canal (dotted lines) are observed. The CBCT image $(A)$ has considerably higher spatial resolution than the MDCT image $(B)$ (voxel size, $0.09 \mathrm{~mm}$ versus 0.625 $\mathrm{mm})$.

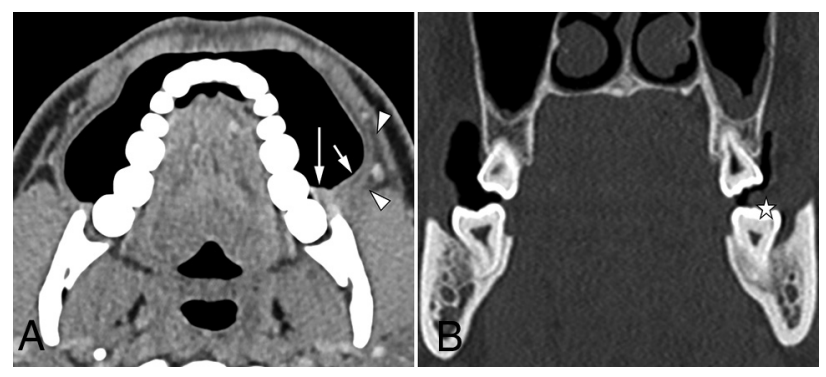

FIG 3. Pericoronitis. Axial contrast-enhanced $C T(A)$ image shows thickening and enhancement of pericoronal tissues around the left mandibular third molar (long arrow), thickening of the adjacent buccinator-buccal mucosa complex (short arrow), and stranding of the left buccal space (arrowheads). Coronal CT (B) image shows that this tooth is partially erupted and covered by thickened gingiva (star). The "puffed-cheek" technique distends the oral cavity with air, helping to detect these abnormalities more accurately. exposure and has higher spatial resolution than MDCT (Fig 2). ${ }^{10}$ Whereas MDCT produces images of the entire part of the body under examination, CBCT typically provides a small set of different field-of-view sizes, ranging from $4 \mathrm{~cm}$ (ideal for a few teeth) to $>20 \mathrm{~cm}$ in diameter according to the clinical indication. ${ }^{11} \mathrm{CBCT}$ is more suitable for patients who are claustrophobic because it has an open design and is generally performed with the patient in an upright position (seated or standing), but MDCT is performed with the patient lying down. ${ }^{8}$ However, CBCT has the disadvantage of poor image quality for soft tissues. ${ }^{12}$

By contrast, MDCT uses a fan-shaped beam that performs several rotations around the patient to obtain images, commonly in a continuous spiral over the axial plane. MDCT has a shorter acquisition time, thus reducing motion artifacts, such as those caused by breathing and swallowing. A distinctive feature of MDCT is that it affords superior characterization of soft tissue. It is also possible to administer an iodinated-based contrast agent when using this method, which is especially helpful when an infection or tumor is under investigation. ${ }^{9}$ However, compared with CBCT, MDCT has some drawbacks, including a higher cost, a greater amount of space needed to house the equipment, and generation of more metal artifacts. ${ }^{13}$

Postprocessing dental software packages are available for both CBCT and MDCT, though they are usually purchased at an additional cost for MDCT. These software packages produce reformatted panoramic and multiple cross-sectional images along the dental arches and are particularly helpful when planning dental implants. ${ }^{14}$

On MDCT examination, some dynamic maneuvers can be performed to provide more image detail and enhanced accuracy. When evaluating the soft tissues adjacent to the teeth, the "puffed-cheek" technique is of considerable value. In this maneuver, the patient distends the oral cavity with air, separating the gingival and buccal mucosal surfaces, which helps to better depict mucosal lesions (Fig 3). ${ }^{15}$ Metal artifacts from dental hardware can be avoided by acquiring images with the mouth closed and open, moving the artifacts to a different area in the second acquisition. ${ }^{16}$ An alternative strategy is to perform a second acquisition through the oral cavity with the neck flexed or extended (or with the gantry angled) ${ }^{17}$ to cast these artifacts into a different plane.

Metal artifact reduction algorithms can improve the quality of images obtained by CBCT and MDCT, ${ }^{8,18}$ though they may introduce new artifacts into the images. Therefore, images obtained with and without application of these algorithms should always be reviewed together to avoid misinterpretation. ${ }^{18}$

MR imaging is a useful radiation-free tool for evaluation of dentoalveolar disease in selected cases and provides superior soft-tissue contrast. It is the ideal imaging choice for assessment of early bone marrow abnormalities in suspected osteomyelitis, soft tissue infections, and both cystic and solid components of jaw tumors. ${ }^{19-21}$ Moreover, MR imaging neurography can assess the terminal branches of the trigeminal nerve that are in close proximity to the mandibular third molars. ${ }^{22}$ However, MR imaging is an expensive and time-consuming technique that has lower spatial resolution than $\mathrm{CT} .^{21}$

\section{THIRD MOLAR IMPACTION}

Tooth impaction is a pathologic condition in which complete eruption into a normal functional position is prevented because 


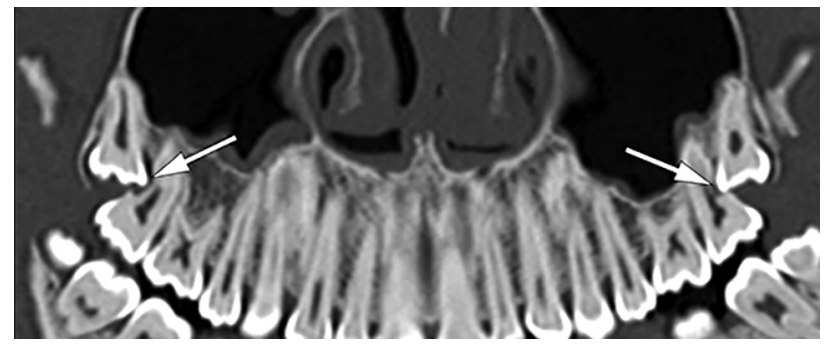

FIG 4. Panoramic reformatted CT image shows impacted unerupted maxillary third molars causing external root resorption of the maxillary second molars (arrows).

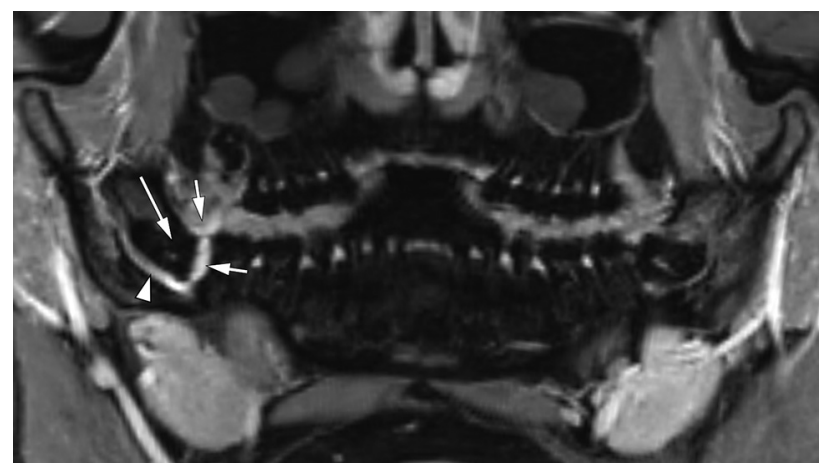

FIG 5. Pericoronitis. Panoramic reformatted contrast-enhanced T7weighted MR image shows enhancement of the soft tissues (short arrows) around the crown of the horizontally impacted right mandibular third molar (long arrow) as well as in the right mandibular canal (arrowhead).

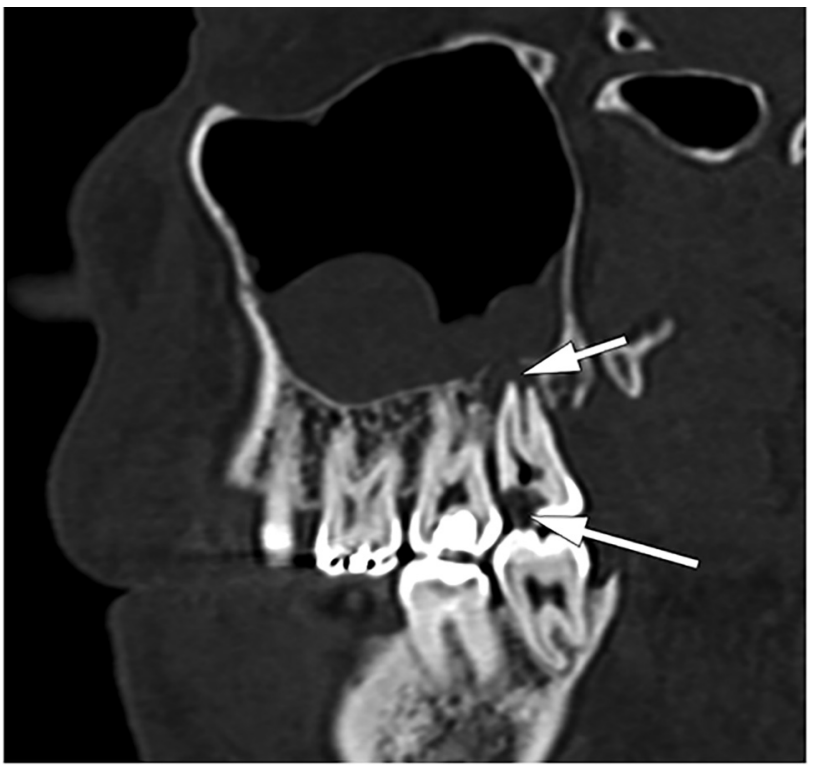

FIG 6. Odontogenic sinusitis. Oblique sagittal CT image shows mucosal thickening of the maxillary sinus associated with a bone defect (short arrow) that communicates the sinus floor with periapical disease of a third molar with a carious lesion (long arrow).

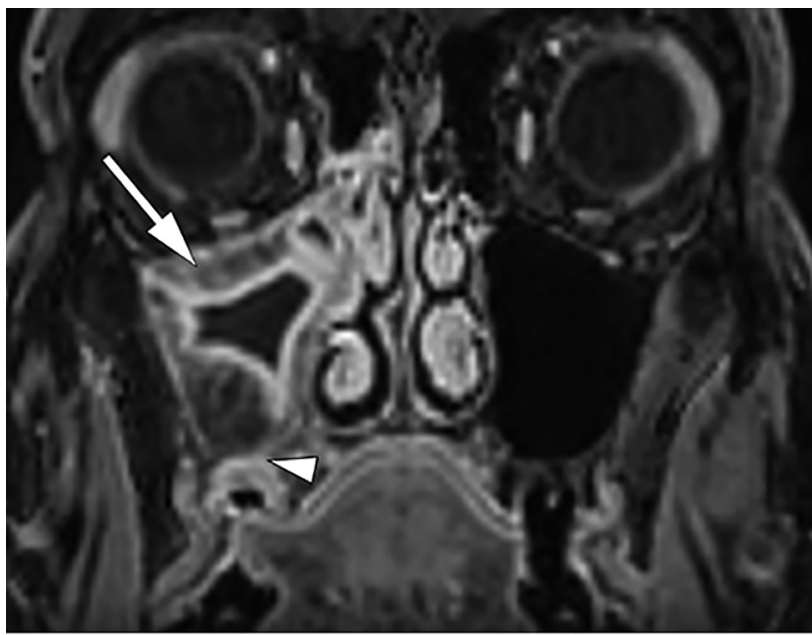

FIG 7. Odontogenic sinusitis following maxillary third molar extraction. Coronal contrast-enhanced T7-weighted MR image shows complete opacification of the right maxillary sinus with mucosal thickening and enhancement (arrow) associated with a bone defect in its floor (third molar socket) (arrowhead).

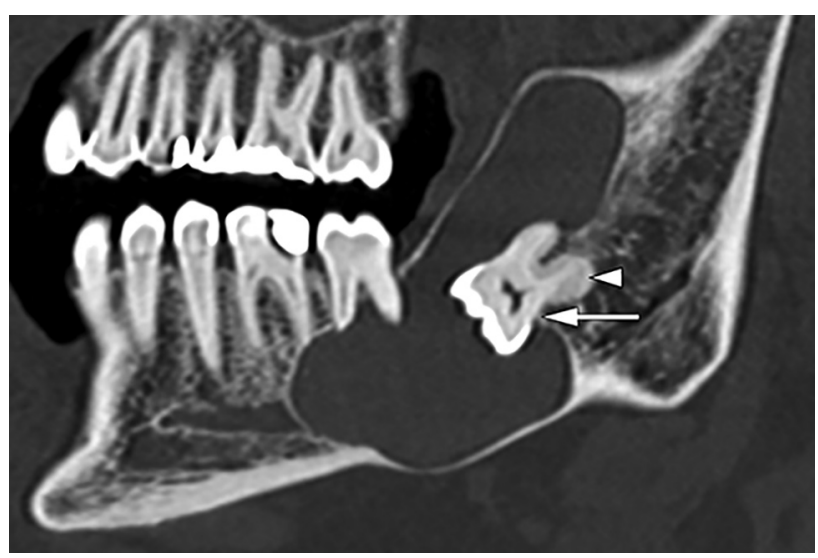

FIG 8. Dentigerous cyst. Oblique sagittal CT image shows an expansile well-defined lesion surrounding an unerupted mandibular third molar that is partially attached in the cementoenamel junction (arrow). Hypercementosis is observed around the roots of this tooth (arrowhead).

of a lack of space, obstruction by another tooth, malposition, or other impediment (Fig 2). ${ }^{1}$ Third molars are the teeth most commonly impacted, with an estimated worldwide prevalence of $24.4 \%{ }^{23}$ Third molar impaction is more frequent in the mandible and has a female predominance. ${ }^{24}$

Impacted third molars can be classified according to their inclination to the long axis of the second molar (eg, mesioangular, distoangular, or horizontal) based on the Archer classification for maxillary third molars and on the Winter classification for mandibular third molars (On-line Figs 1 and 2). ${ }^{25}$

Complete tooth impaction is considered to have occurred when the tooth is entirely covered by bone, soft tissue, or both. A partial tooth impaction is deemed to have occurred when the tooth is visible on oral inspection but has not erupted into a normal functional position. In most cases, impaction occurs when second molars block the path of eruption of third molars. ${ }^{1}$ 
Partially impacted third molars are prone to development of several pathologies, including pericoronitis, carious lesions, and periodontal bone loss, often because of difficulties in reaching them during routine oral hygiene. ${ }^{24,26}$ External root resorption and carious lesions are usually observed on the distal surface of the adjacent second molars as a result of the pressure exerted by impacted third molars (Fig 4). This leads to inflammation and triggers resorption, ultimately resulting in pulp necrosis and loss of the second molars. ${ }^{27,28}$ Conversely, entirely unerupted impacted third molars are more likely to be associated with development of cysts and tumors. ${ }^{29}$

When reporting an impacted third molar, it is important to assess the relationship with the adjacent second molar, the

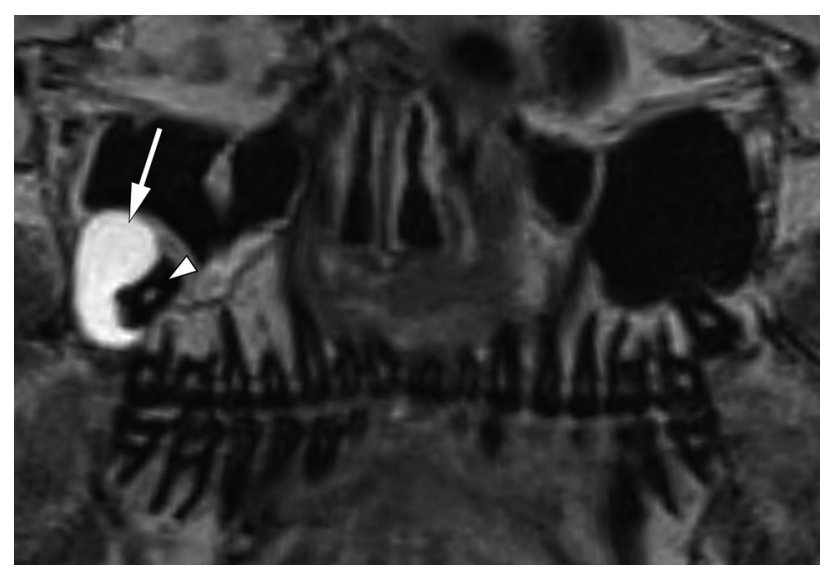

FIG 9. Dentigerous cyst. Panoramic reformatted FLAIR MR image shows an expansile and homogeneous well-defined lesion (arrow) surrounding the crown of the unerupted right maxillary third molar (arrowhead), superiorly displacing the maxillary sinus floor. number of roots and their morphology (convergent, divergent, and/or fused), and in particular the relationship between the tooth and the mandibular canal or maxillary sinus floor. The status of the surrounding bone and any associated pathologies, such as periapical lesions and coronal or pericoronal lucencies, should also be described. ${ }^{30}$ In some cases, hypercementosis may be observed. Hypercementosis refers to excessive deposition of cementum around the roots of a tooth (Fig 2); it does not alter tooth vitality but can pose difficulties during dental procedures such as extraction and endodontic treatment. ${ }^{31}$

\section{PERICORONITIS}

Pericoronitis is an infection of the soft tissue surrounding the crown of a partially erupted tooth, usually the mandibular third molar, which is frequently impacted and partially covered by gingiva. Food debris lodges beneath the overlying gingiva, which is subsequently infected by bacteria. ${ }^{3,20}$ Infection might spread to the surrounding tissue, including the alveolar bone and deep neck spaces, potentially evolving into an abscess. On imaging, pericoronitis typically appears as thickening and enhancement of the pericoronal tissues of a partially erupted tooth (Figs 3 and 5). ${ }^{16}$ Contrast-enhanced CT and MR imaging are able to evaluate the spread of infection to surrounding tissues. ${ }^{20}$ Dynamic maneuvers, such as the "puffed-cheek" technique, can enhance accuracy when evaluating the gingiva. ${ }^{15}$

\section{ODONTOGENIC SINUSITIS}

Maxillary third molars can be a source of odontogenic sinusitis. For practical purposes, their etiologies can be divided into dental disease (mainly periapical) and iatrogenic. Iatrogenic sources include postdental extraction, inadequate positioning of dental implant fixtures, infected retained roots, and foreign bodies (eg, extruded root canal fillings). ${ }^{6,32}$

$\mathrm{CT}$ is the best imaging method for diagnosis of odontogenic sinusitis. CT demonstrates maxillary sinus disease with a bone defect in the maxillary sinus floor, which is typically associated with dental disease or complications of dental procedures (Figs 6 and 7). Maxillary sinus disease begins as an asymptomatic mucosal thickening in the floor and can evolve to subtotal or total sinus opacification, potentially occluding the ostiomeatal complex and ultimately leading to frontal and anterior ethmoidal sinusitis. Unilateral sinusitis involving the maxillary sinus or the anterior sinuses should raise suspicion for an odontogenic process; therefore, the maxillary sinus floor, posterior maxillary teeth, and alveolar process should be investigated carefully for abnormalities. ${ }^{6,33}$
FIG 10. Odontogenic keratocyst. Oblique sagittal CT (A) image shows an expansile, well-defined lesion (arrow) in the left mandibular angle in contact with the distal surface of the unerupted third molar, inferiorly displacing the mandibular canal (arrowhead). Axial T1-weighted (B) and T2weighted $(C)$ MR images of the same patient show the lesion to be heterogeneous but predominantly isointense to hyperintense on TTWI and hyperintense on T2WI (arrows). Axial contrastenhanced T7-weighted $(D)$ image shows thin peripheral enhancement (arrow). Diffusion-weighted image $(E)$ and the corresponding ADC map $(F)$ reveal restricted diffusion (arrows). 


\section{CYSTS AND TUMORS}

Unerupted impacted third molars are prone to development of odontogenic cysts and tumors, particularly dentigerous cysts, odontogenic keratocysts, and ameloblastomas. ${ }^{29}$
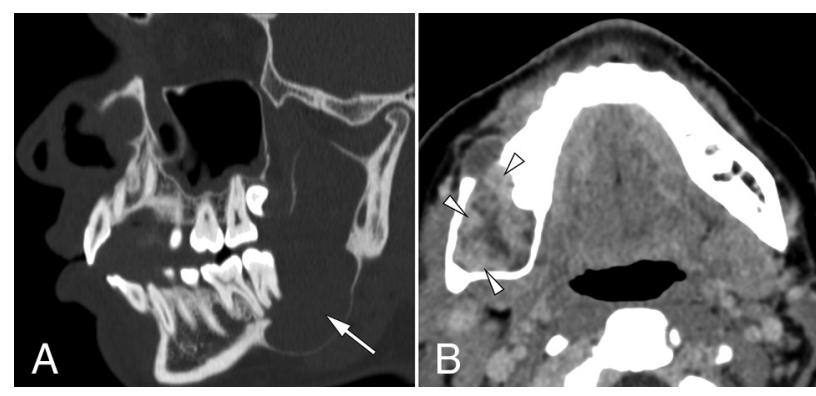

FIG 11. Ameloblastoma. Oblique sagittal (A) and axial contrastenhanced (B) CT images show a unilocular, expansile lesion in the right mandibular angle (arrow) with marked cortical thinning, buccolingual expansion, and internal solid mural nodules (arrowheads). (Case courtesy of Eloisa S. Gebrim, MD, PhD, InRad, University of São Paulo, Brazil.)

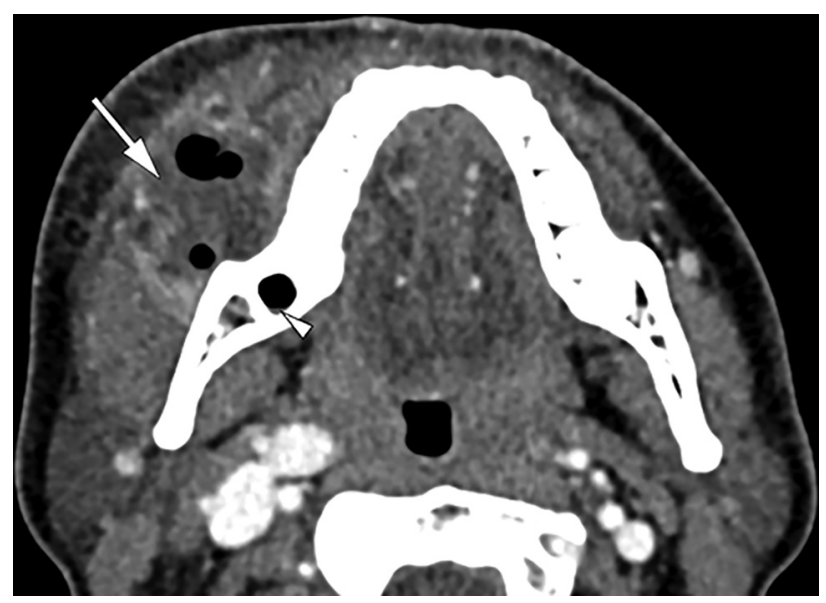

FIG 12. Abscess after dental extraction. Axial contrast-enhanced CT image shows an abscess (arrow) near the right mandibular third molar socket (arrowhead).
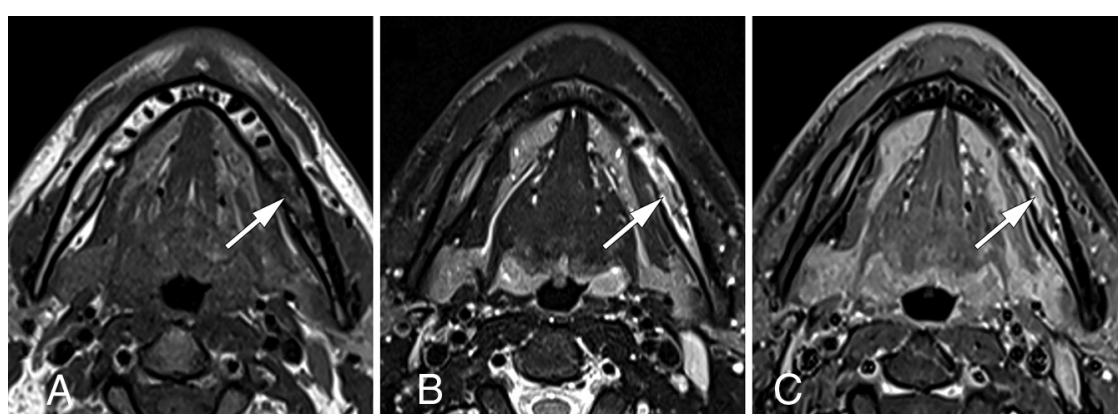

FIG 13. Acute osteomyelitis of the mandible after extraction of the left first and third molars. Axial T1-weighted (A), fat-saturated T2-weighted (B), and contrast-enhanced T1-weighted (C) MR images show signal intensity abnormalities and enhancement of the bone marrow in the left mandibular body (arrows).
Dentigerous cysts, also called follicular cysts, are the most common noninflammatory odontogenic cysts, arising around the crown of an unerupted or impacted tooth, most frequently the mandibular third molar. ${ }^{34}$ On CT, the classic presentation of a dentigerous cyst is a unilocular radiolucent lesion attached to the cementoenamel junction of an unerupted or impacted tooth. ${ }^{29}$ On MR imaging, dentigerous cysts typically show low signal intensity on T1-weighted images and high signal intensity on T2weighted images with a thin enhancing ring (Figs 8 and 9). However, they may appear hyperintense on T1-weighted images because of the presence of cholesterol crystals or proteinaceous material. $^{34}$

Odontogenic keratocysts are lesions constituted by a cystic space containing desquamated keratin and occur more frequently in the mandible, mainly in the posterior regions. Although they are histologically benign lesions, they are usually locally aggressive with a relatively high recurrence rate. ${ }^{35}$ On CT, odontogenic keratocysts typically appear as radiolucent, unilocular, expansile lesions with smooth and often scalloped margins. In the mandible, they tend to grow along the length of the bone, causing relatively minimal buccolingual expansion. If associated with the crown of an unerupted tooth, an odontogenic keratocyst can mimic a dentigerous cyst. Large odontogenic keratocysts can present as septate or multiloculated lesions that may simulate ameloblastoma. On MR imaging, odontogenic keratocysts usually show diffuse heterogeneous signal intensity on T1- and T2-weighted images (ranging from low to high) with a thin enhancing ring. ${ }^{19,34,36}$ DWI has proved to be a useful adjuvant tool for differentiating odontogenic lesions; odontogenic keratocysts tend to have lower ADC values because of their high level of desquamated keratin, especially compared with ameloblastomas (Fig 10). ${ }^{36,37}$

Ameloblastoma is a benign but locally aggressive odontogenic tumor that is more common in the posterior mandible. CT features include a uniloculated or multiloculated expansile lesion, commonly with a "soap-bubble" or honeycombed pattern accompanied by remodeling and cortical thinning. Resorption of the roots of adjacent teeth is also common. Unlike odontogenic keratocysts, ameloblastomas have a propensity for buccolingual expansion in the mandible. ${ }^{35,38} \mathrm{MR}$ imaging typically reveals high signal intensity on T2-weighted images. Both contrastenhanced CT and MR imaging show enhancing septations, mural nodules, or both in classic cases; these enhancing components are more easily detectable on MR imaging scans, which are also useful for evaluating extraosseous components, including involvement of neurovascular structures (Fig 11 and On-line Fig 3). ${ }^{19,38}$ Unicystic ameloblastoma is a subtype encountered less often and can mimic a dentigerous cyst or odontogenic keratocyst. ${ }^{29}$

\section{COMPLICATIONS OF THIRD MOLAR EXTRACTION}

Complications of third molar extraction occur in $3.5 \%$ to $14.8 \%$ of patients ${ }^{2}$ and are more common in the 

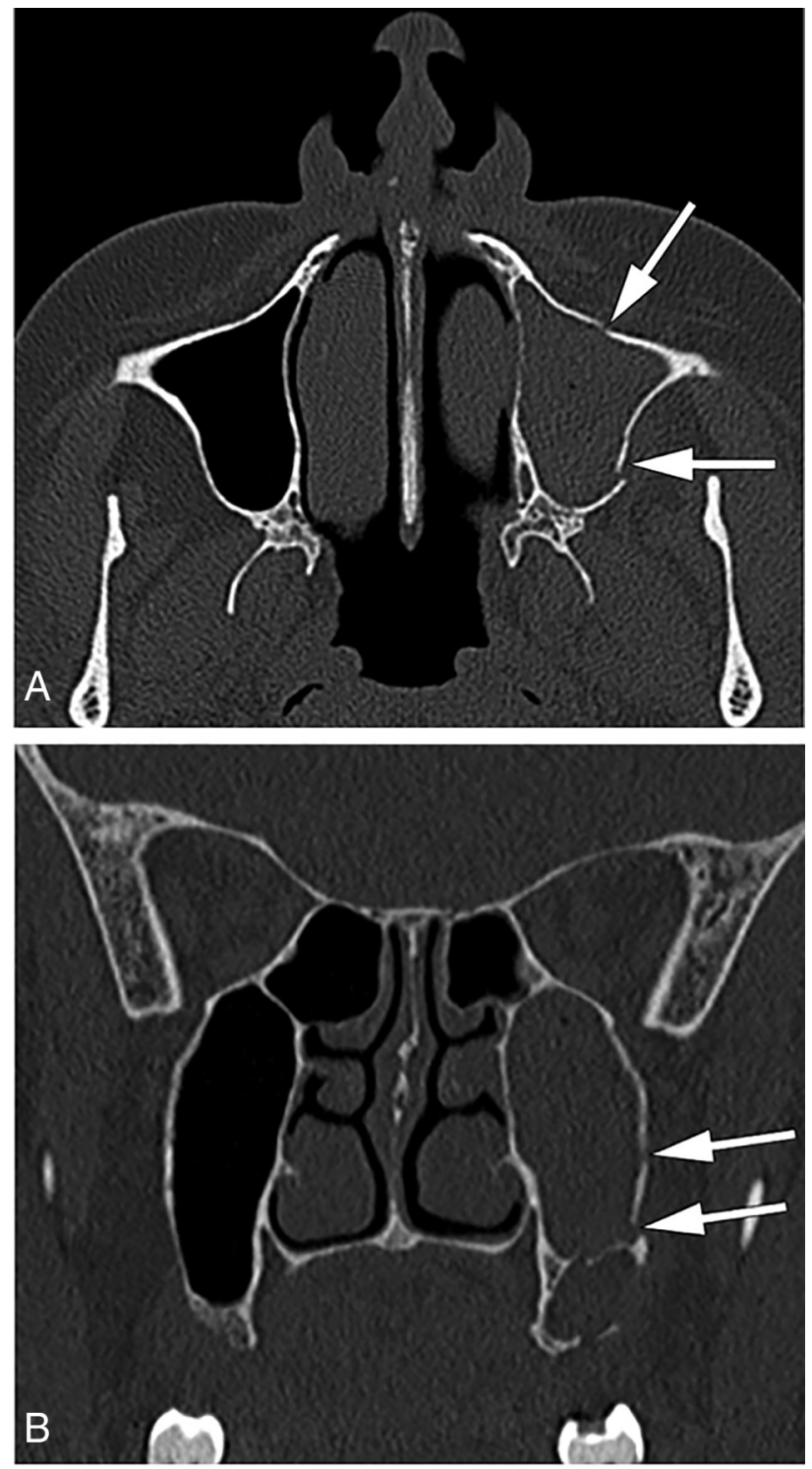

FIG 14. Fracture of the maxillary sinus walls after third molar extraction. Axial $(A)$ and coronal $(B) C T$ images show fractures of the anterior and lateral walls of the left maxillary sinus (arrows) with complete opacification of the sinus.

mandibular third molars. ${ }^{39}$ Many of these complications are related to a greater degree of tooth impaction. ${ }^{2,40}$ Complications of dental extraction range from mild local discomfort to serious conditions requiring hospitalization or resulting in sequelae. ${ }^{41}$

Infection is one of the most frequent complications after third molar removal ${ }^{41}$ and often starts at the surgical site. ${ }^{40}$ It can extend to the adjacent soft tissue, leading to cellulitis, myositis, and abscess. Contrast-enhanced CT is the first-line imaging technique for a suspected abscess, which appears as a fluid collection with rim enhancement near the tooth socket, sometimes with gas bubbles, and is frequently associated with surrounding inflammatory changes (Fig 12). Immediate postprocedural soft tissue emphysema is a common finding unless other infectious findings such as abscess or cellulitis are also present. CT is also useful for assessing the bone status

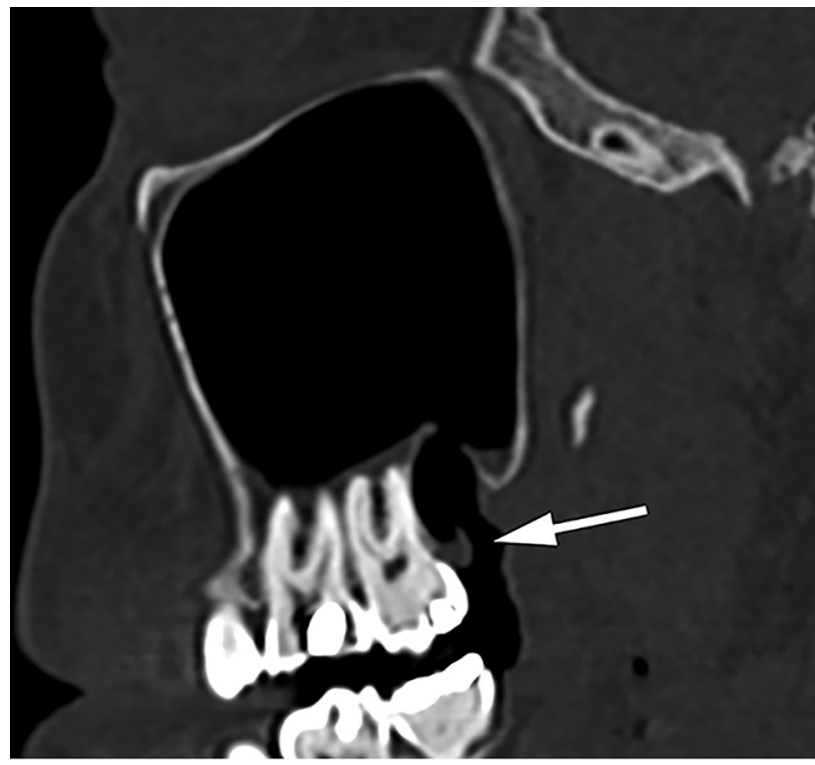

FIG 15. Oroantral fistula after third molar extraction. Sagittal CT image shows an air-filled gap (arrow) between the maxillary sinus and the oral cavity through the tooth socket.

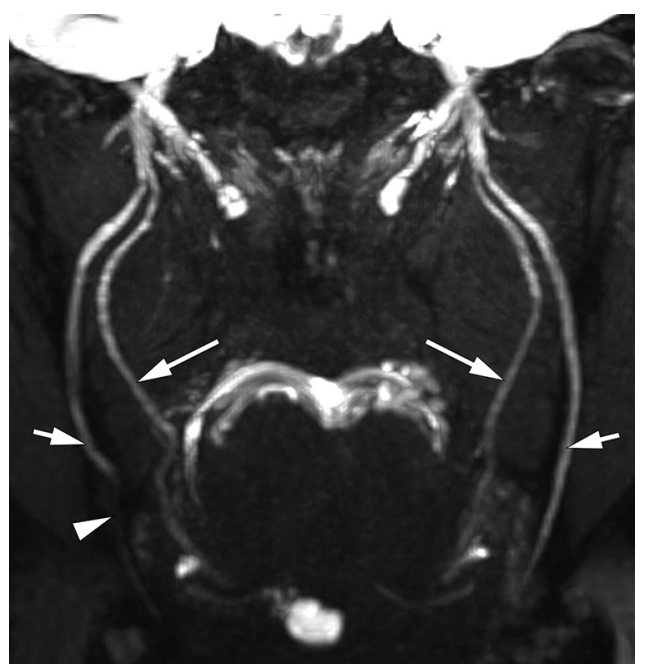

FIG 16. Right inferior alveolar nerve injury after third molar extraction. Coronal MR neurography image of the lingual (long arrows) and inferior alveolar (short arrows) nerves shows a discontinuity in the right inferior alveolar nerve (arrowhead). The remaining nerves have a normal caliber and signal intensity.

in the surgical site and may depict other complications, such as retained tooth fragments and osteomyelitis. ${ }^{42}$

Osteomyelitis develops when an infection reaches the bone marrow. In the acute phase, MR imaging is the best method for detection of early bone marrow signal abnormalities, observed as low signal on T1-weighted images and high signal on T2weighted images with enhancement on postcontrast sequences (Fig 13). CT is ideal for depicting bone erosion and periosteal reaction. In the chronic phase, bone sclerosis and sequestrum can be observed. Soft tissue edema, cellulitis, and abscess are common findings in both phases. ${ }^{20}$ 


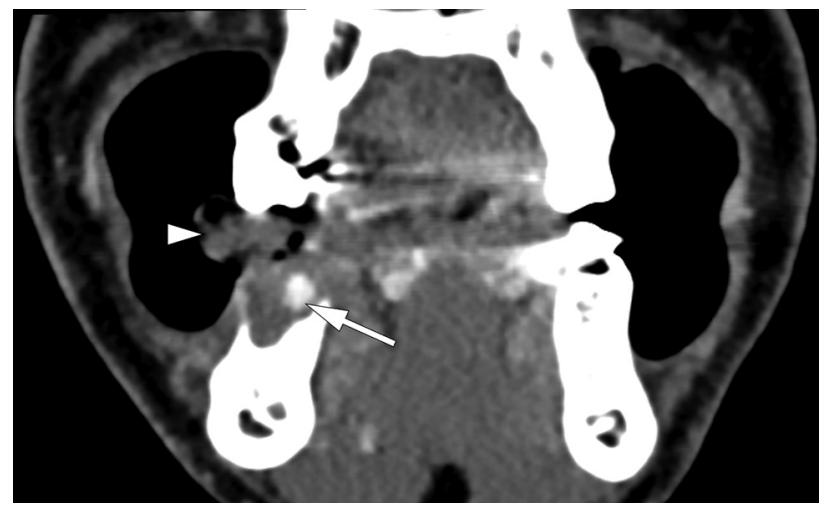

FIG 17. Active bleeding in the tooth socket. Coronal contrastenhanced CT image shows a focus of active extravasation of contrast material in the tooth socket after extraction (arrow). The patient is biting a gauze pad (arrowhead).

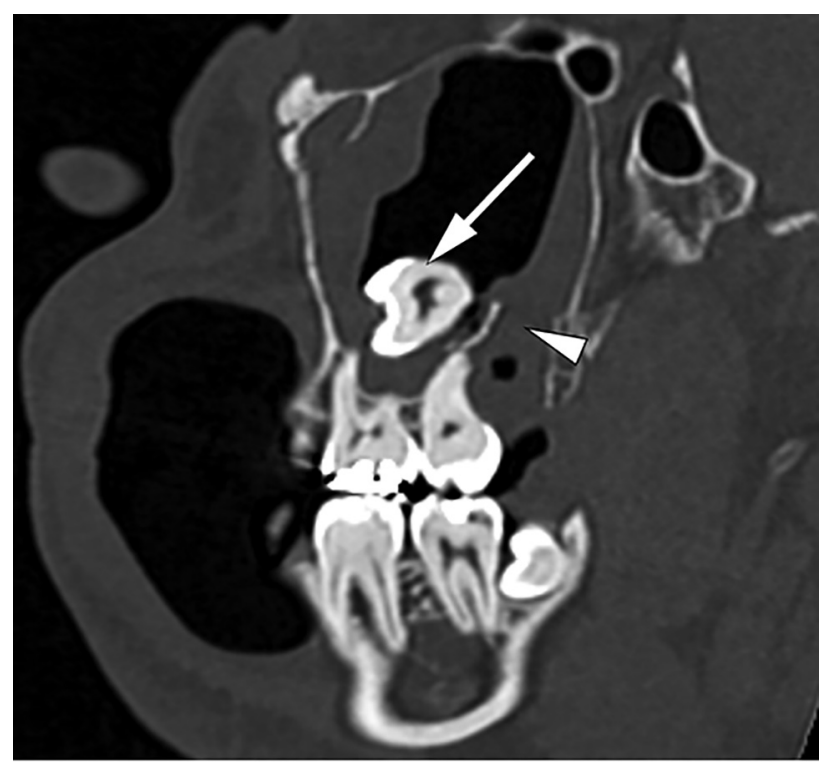

FIG 18. Accidental third molar displacement into the maxillary sinus. Oblique sagittal CT image shows a third molar displaced into the maxillary sinus (arrow) and rupture of the maxillary sinus floor (arrowhead) with nearby small bone fragments.

Alveolar osteitis, also called "dry socket," is a clinical diagnosis characterized by development of intense throbbing pain several days after dental extraction and is often associated with halitosis. Alveolar osteitis is a frequent complication of tooth removal and is related to partial or complete loss of the blood clot in the tooth socket. ${ }^{40,41}$ Oral examination findings include a cryptlike socket with exposed bone and erythematous borders, food debris, and other detritus in the socket. Imaging examinations are useful for exclusion of other complications, such as a residual tooth fragment and fracture. ${ }^{43}$

Fractures may affect the alveolar processes of the maxilla and mandible; the body, angle, and ramus of the mandible; the maxillary tuberosity; and the floor and walls of the maxillary sinus. CT is the criterion standard imaging method for evaluation of

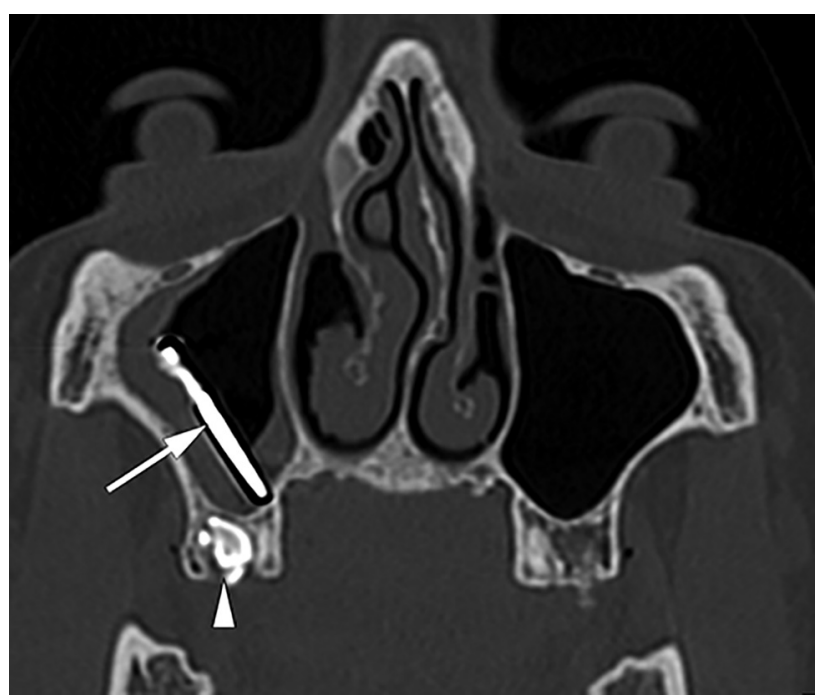

FIG 19. Accidental displacement of a foreign body into the maxillary sinus. Coronal CT image shows a dental bur (arrow) displaced into the right maxillary sinus. Fragmentation of the right maxillary third molar is also observed (arrowhead).

fractures, which appear as lucent noncorticated lines with variable deviation and angulation of the fragments (Fig 14). ${ }^{40,44}$

Communication between the maxillary sinus and tooth socket can occur during extraction of a maxillary third molar. If this connection is smaller than $2 \mathrm{~mm}$, it generally closes spontaneously ${ }^{45}$; however, if this communication becomes epithelialized (which takes $\sim 7$ days), it becomes an oroantral fistula. ${ }^{6} \mathrm{CT}$ is the best imaging technique to diagnose oroantral fistula, which appears as an air connection between the maxillary sinus and the oral cavity (Fig 15). The "puffedcheek" technique (described earlier) may help detect this air passageway. ${ }^{16}$

Mandibular third molar extraction may cause injuries to the peripheral branches of the trigeminal nerve, particularly the inferior alveolar and lingual nerves. Abnormalities can be accurately diagnosed by MR neurography as areas of increased T2 signal intensity, changes in the caliber of the nerve, or discontinuities (Fig 16). ${ }^{22,46}$ Unerupted teeth, horizontal impaction, and root apices inside or in contact with the mandibular canal are associated with an increased risk of inferior alveolar nerve injury, whereas unerupted teeth, distoangular impaction, and the lingual bone split surgical technique are considered risk factors for lingual nerve injury. ${ }^{47,48}$

Hemorrhage may occur during or after third molar removal; rarely, foci of active bleeding can appear as contrast-material extravasation inside or near the tooth socket (Fig 17). ${ }^{16}$

Accidental displacement of the third molar into adjacent spaces, such as the parapharyngeal space or maxillary sinus (Fig 18), is another possible complication after extraction attempts. Foreign bodies, such as root fragments and dental instruments, may also be introduced into the maxillary sinus during extraction (Fig 19). ${ }^{49-51}$

Rarely, emphysema in the subcutaneous and deep neck spaces can result from forced injection of pressurized air 

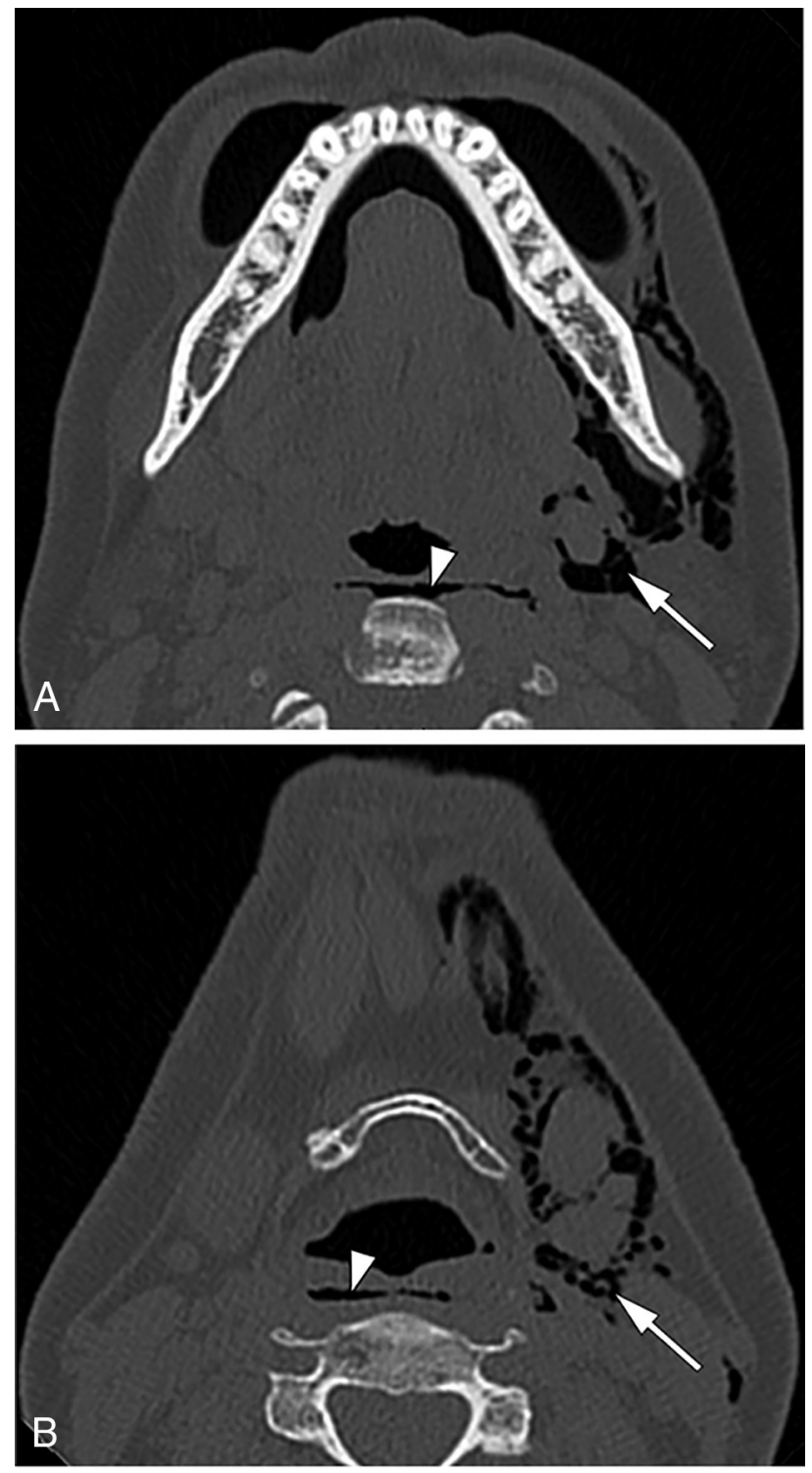

FIG 20. Emphysema following a dental procedure. Axial CT images show extensive deep emphysema in the left face and neck (arrows) as well as in the retropharyngeal or danger space (arrowheads).

from dental drills into the surgical site (Fig 20). ${ }^{52,53}$ Finally, overeruption of the opposing third molar is considered a late adverse event, which can lead to tooth misalignment and occlusal disability (Fig 21). ${ }^{54}$

\section{CONCLUSIONS}

The increasing sophistication of cross-sectional imaging techniques plays a pivotal role in diagnosing third molar-related conditions, which can be challenging for radiologists who are inexperienced in dental imaging. Comprehensive knowledge of the imaging characteristics of these abnormalities helps the practicing radiologist arrive at a correct diagnosis, thus improving patient care.

\section{ACKNOWLEDGMENT}

The authors thank Rodrigo Tonan for the tooth illustrations.

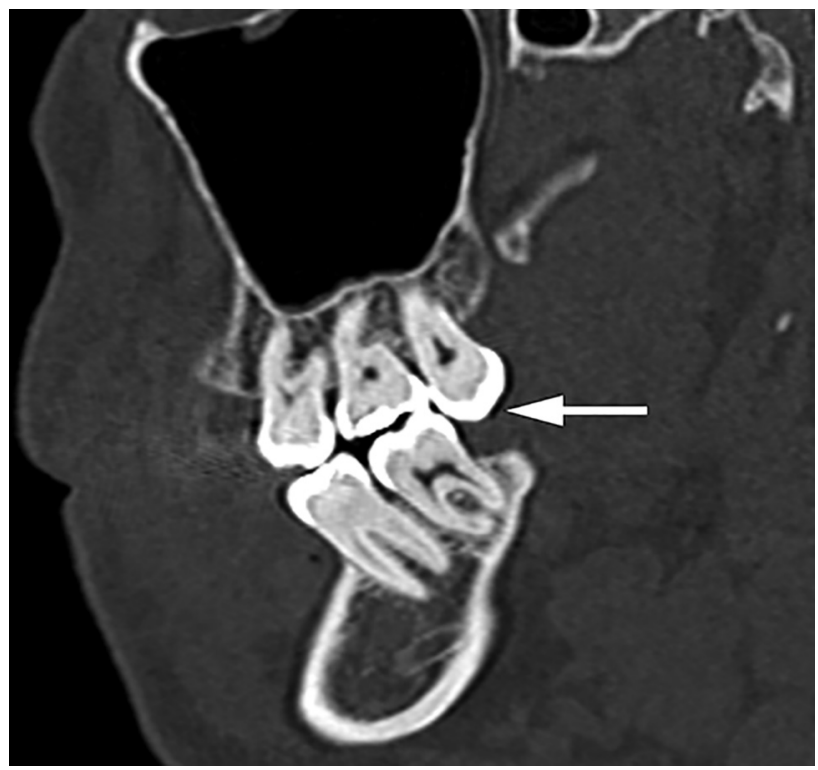

FIG 21. Sagittal CT image shows overeruption of the maxillary third molar (arrow) caused by previous extraction of the opposing third molar.

\section{REFERENCES}

1. Ghaeminia H, Perry J, Nienhuijs ME, et al. Surgical removal versus retention for the management of asymptomatic disease-free impacted wisdom teeth. Cochrane Database Syst Rev 2016;CD003879 CrossRef Medline

2. Miclotte I, Agbaje JO, Spaey Y, et al. Incidence and treatment of complications in patients who had third molars or other teeth extracted. Br J Oral Maxillofac Surg 2018;56:388-93 CrossRef Medline

3. Scheinfeld MH, Shifteh K, Avery LL, et al. Teeth: what radiologists should know. Radiographics 2012;32:1927-44 CrossRef Medline

4. Husain MA. Dental anatomy and nomenclature for the radiologist. Radiology Clin North Am 2018;56:1-11 CrossRef Medline

5. Zohrabian VM, Poon CS, Abrahams JJ. Embryology and anatomy of the jaw and dentition. Semin Ultrasound CT MR 2015;36:397406 CrossRef Medline

6. Whyte A, Boeddinghaus R. Imaging of odontogenic sinusitis. Clin Radiol 2019;74:503-16 CrossRef Medline

7. Aksoy U, Aksoy S, Orhan K. A cone-beam computed tomography study of the anatomical relationships between mandibular teeth and the mandibular canal, with a review of the current literature. Microsc Res Tech 2018;81:308-14 CrossRef

8. Nasseh I, Al-Rawi W. Cone beam computed tomography. Dent Clin North Am 2018;62:361-91 CrossRef Medline

9. Gohel A, Oda M, Katkar AS, et al. Multidetector row computed tomography in maxillofacial imaging. Dent Clin North Am 2018;62:45365 CrossRef Medline

10. Nardi $C$, Talamonti $C$, Pallotta $S$, et al. Head and neck effective dose and quantitative assessment of image quality: a study to compare cone beam CT and multislice spiral CT. Dentomaxillofac Radiol 2017;46:20170030 CrossRef Medline

11. Schulze RK, Drage NA. Cone-beam computed tomography and its applications in dental and maxillofacial radiology. Clin Radiol 2020; May 23 [Epub ahead of print] CrossRef Medline

12. Miracle AC, Mukherji SK. Conebeam CT of the head and neck, part 1: physical principles. AJNR Am J Neuroradiol 2009;30:1088-95 CrossRef Medline 
13. Chindasombatjaroen J, Kakimoto N, Murakami S, et al. Quantitative analysis of metallic artifacts caused by dental metals: comparison of cone-beam and multi-detector row CT scanners. Oral Radiology 2011;27:114-20 CrossRef

14. Scarfe WC, Toghyani S, Azevedo B. Imaging of benign odontogenic lesions. Radiol Clin North Am 2018;56:45-46 CrossRef Medline

15. Weissman JL, Carrau RL. "Puffed-cheek" CT improves evaluation of the oral cavity. AJNR Am J Neuroradiol 2001;22:741-44 Medline

16. Loureiro RM, Naves EA, Zanello RF, et al. Dental emergencies: a practical guide. Radiographics 2019;39:1782-95 CrossRef Medline

17. Barrett JF, Keat N. Artifacts in CT: recognition and avoidance. Radiographics 2004;24:1679-91 CrossRef Medline

18. Katsura M, Sato J, Akahane M, et al. Current and novel techniques for metal artifact reduction at CT: practical guide for radiologists. Radiographics 2018;38:450-61 CrossRef Medline

19. Meyer KA, Bancroft LW, Dietrich TJ, et al. Imaging characteristics of benign, malignant, and infectious jaw lesions: a pictorial review. AJR Am J Roentgenol 2011;197:W412-21 CrossRef Medline

20. Mardini S, Gohel A. Imaging of odontogenic infections. Radiol Clin North Am 2018;56:31-44 CrossRef Medline

21. Demirturk Kocasarac H, Geha H, Gaalaas LR, et al. MRI for dental applications. Dent Clin North Am 2018;62:467-80 CrossRef Medline

22. Dessouky R, Xi Y, Zuniga J, et al. Role of MR neurography for the diagnosis of peripheral trigeminal nerve injuries in patients with prior molar tooth extraction. AJNR Am J Neuroradiol 2018;39:16269 CrossRef Medline

23. Carter K, Worthington S. Predictors of third molar impaction: a systematic review and meta-analysis. J Dent Res 2016;95:267-76 CrossRef Medline

24. Shoshani-Dror D, Shilo D, Ginini JG, et al. Controversy regarding the need for prophylactic removal of impacted third molars: an overview. Quintessence Int 2018;49:653-62 CrossRef Medline

25. Miclotte A, Grommen B, Cadenas de Llano-Pérula M, et al. The effect of first and second premolar extractions on third molars: a retrospective longitudinal study. J Dent 2017;61:55-66 CrossRef Medline

26. Steed MB. The indications for third-molar extractions. J Am Dent Assoc 2014;145:570-73 CrossRef Medline

27. Tassoker $\mathrm{M}$. What are the risk factors for external root resorption of second molars associated with impacted third molars? A conebeam computed tomography study. J Oral Maxillofac Surg 2019;77:1117 CrossRef Medline

28. Consolaro A, Bittencourt G. Why not to treat the tooth canal to solve external root resorptions? Here are the principles! Dental Press J Orthod 2016;21:20-22 CrossRef Medline

29. Mortazavi H, Baharvand M. Jaw lesions associated with impacted tooth: a radiographic diagnostic guide. Imaging Sci Dent 2016;46:14757 CrossRef Medline

30. Matzen LH, Wenzel A. Efficacy of CBCT for assessment of impacted mandibular third molars: a review-based on a hierarchical model of evidence. Dentomaxillofac Radiol 2015;44:20140189 CrossRef Medline

31. Patil SR, Araki K, Yadav N, et al. Prevalence of hypercementosis in a Saudi Arabian population: a cone beam computed tomography study. J Oral Res 2018;7:94-97 CrossRef Medline

32. Kim SM. Definition and management of odontogenic maxillary sinusitis. Maxillofac Plast Reconstr Surg 2019;41:13 CrossRef Medline

33. Little RE, Long CM, Loehrl TA, et al. Odontogenic sinusitis: a review of the current literature. Laryngoscope Investig Otolaryngol 2018;3:110-14 CrossRef Medline

34. Mosier KM. Lesions of the jaw. Semin Ultrasound CT MR 2015;36:44450 CrossRef Medline
35. Bilodeau EA, Collins BM. Odontogenic cysts and neoplasms. Surg Pathol Clin 2017;10:177-222 CrossRef Medline

36. Borghesi A, Nardi C, Giannitto C, et al. Odontogenic keratocyst: imaging features of a benign lesion with an aggressive behaviour. Insights Imaging 2018;9:883-97 CrossRef Medline

37. Sumi M, Ichikawa Y, Katayama I, et al. Diffusion-weighted MR imaging of ameloblastomas and keratocystic odontogenic tumors: differentiation by apparent diffusion coefficients of cystic lesions. AJNR Am J Neuroradiol 2008;29:1897-901 CrossRef Medline

38. Oren N, Vaysberg A, Ginat DT. Updated WHO nomenclature of head and neck lesions and associated imaging findings. Insights Imaging 2019;10:72 CrossRef Medline

39. Contar CM, de Oliveira P, Kanegusuku K, et al. Complications in third molar removal: a retrospective study of 588 patients. Med Oral Patol Oral Cir Bucal 2010;15:e74-78 CrossRef Medline

40. Deliverska EG, Petkova M. Complications after extraction of impacted third molars-literature review. J IMAB 2016;22:1202-11 CrossRef

41. Bouloux GF, Steed MB, Perciaccante VJ. Complications of third molar surgery. Oral Maxillofac Surg Clin North Am 2007;19:117-28 CrossRef Medline

42. Capps EF, Kinsella JJ, Gupta M, et al. Emergency imaging assessment of acute, nontraumatic conditions of the head and neck. Radiographics 2010;30:1335-52 CrossRef Medline

43. Susarla SM, Smart RJ, Dodson TB. Complications associated with dentoalveolar surgery. In: Andersson L, Kahnberg KE, Pogrel MA, eds. Oral and Maxillofacial Surgery. Blackwell; 2010:155-63

44. Chrcanovic BR, Custódio AL. Considerations of mandibular angle fractures during and after surgery for removal of third molars: a review of the literature. Oral Maxillofac Surg 2010;14:71-80 CrossRef Medline

45. Kretzschmar DP, Kretzschmar JL. Rhinosinusitis: review from a dental perspective. Oral Surg Oral Med Oral Pathol Oral Radiol Endod 2003;96:128-35 CrossRef Medline

46. Cox B, Zuniga JR, Panchal N, et al. Magnetic resonance neurography in the management of peripheral trigeminal neuropathy: experience in a tertiary care centre. Eur Radiol 2016;26:3392-400 CrossRef Medline

47. Juodzbalys G, Daugela P. Mandibular third molar impaction: review of literature and a proposal of a classification. J Oral Maxillofac Res 2013;4:e1 CrossRef Medline

48. Leung YY, Cheung LK. Risk factors of neurosensory deficits in lower third molar surgery: a literature review of prospective studies. Int J Oral Maxillofac Surg 2011;40:1-10 CrossRef Medline

49. Iwai $\mathrm{T}$, Chikumaru $\mathrm{H}$, Shibasaki M, et al. Safe method of extraction to prevent a deeply-impacted maxillary third molar being displaced into the maxillary sinus. Br J Oral Maxillofac Surg 2013;51:e75-6-e76 CrossRef Medline

50. Hara Y, Shiratsuchi H, Tamagawa T, et al. A large-scale study of treatment methods for foreign bodies in the maxillary sinus. J Oral Sci 2018;60:321-28 CrossRef Medline

51. Di Nardo D, Mazzucchi G, Lollobrigida M, et al. Immediate or delayed retrieval of the displaced third molar: a review. J Clin Exp Dent 2019;11:e55-61 CrossRef Medline

52. Romeo U, Galanakis A, Lerario F, et al. Subcutaneous emphysema during third molar surgery: a case report. Braz Dent J 2011;22:8386 CrossRef Medline

53. Tay YBE, Loh WS. Extensive subcutaneous emphysema, pneumomediastinum, and pneumorrhachis following third molar surgery. Int J Oral Maxillofac Surg 2018;47:1609-12 CrossRef Medline

54. Craddock HL. An investigation of overeruption of posterior teeth with partial occlusal contact. J Oral Rehabil 2007;34:246-50 CrossRef Medline 